
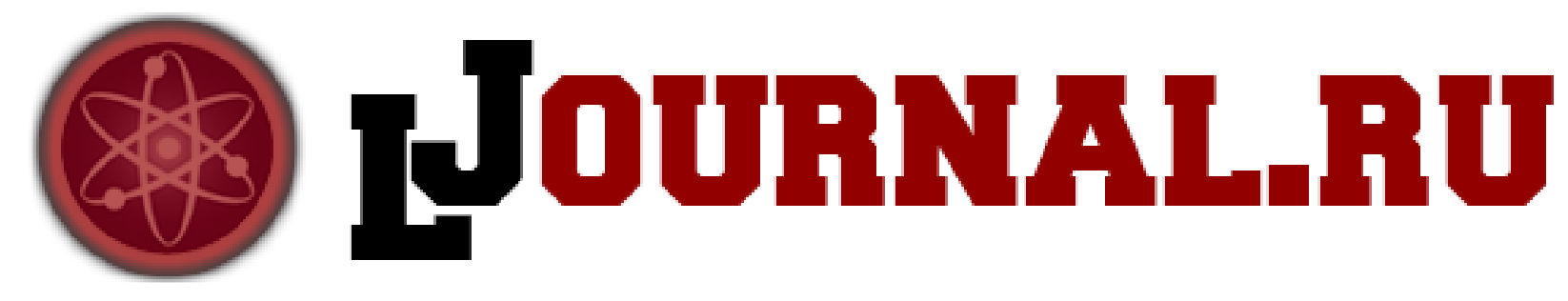

Злобин А.А.

Пермский национальный исследовательский политехнический университет

Пермь, Россия

doi: 10.18411/1j2016-2-08

\title{
Изучение фрактальных свойств нефтяных дисперсных систем
}

Одним из приоритетных направлений повышения нефтеотдачи пластов и добычи нефти является разработка и внедрение современных нанотехнологий, которые уже давно используются в биологии, медицине, электронике, металлургии, физике покрытий, но достаточно слабо приживаются в нефтяной отрасли, хотя последние несут в себе огромный потенциал увеличения технологической эффективности всех процессов нефтепромыслового дела. Такое заметное отставание объясняется отсутствием фундаментальных знаний о структуре и кинетике нефтяных дисперсных систем (НДС) в условиях промысла при добыче углеводородов. На современном этапе задача управления свойствами НДС при разработке залежи уже не может решаться традиционным знанием элементного, группового, фракционного и химического составов добываемых нефтей. В настоящее время назрела объективная необходимость к переходу к более тонким нанотехнологиям по воздействию на свойства пластовых флюидов, основанных на базовых принципах самоорганизации сложных структурно-динамических систем. В связи с этим актуальными остаются задачи исследования структурной организации нефтяных дисперсных систем современными физическими in situ методами в естественных условиях продуктивного пласта. Целью данной работы является изучение наноструктуры 
реальных сырых нефтей, начатое автором ранее [1, 2], а именно, описание, так называемых, фрактальных свойств НДС. Как известно, учет фрактальных свойств агрегатов ведет к пересмотру основ классической гидродинамики, сдвиговых деформаций, седиментации, адсорбции, капиллярных эффектов, химической активности и прочее.

\section{Моделирование роста фрактальных асфальтеновых агрегатов}

Добываемая из залежи нефть представляет собой природную коллоидную дисперсную систему, характерная особенность которой заключается в существовании в ней, так называемых, надмолекулярных структур (НMC) внутренних адсорбционных комплексов, построенных из молекул асфальтенов и смол, размеры которых в 10-1000 раз больше молекулярных. Основная роль в образовании НМС отводится молекулам нефтяных асфальтенов. Они являются продуктами высокотемпературных катагенетических превращений углеводородов и обладают высокой склонностью к ассоциации и агрегированию за счет парамагнитной природы комплексов [3]. Асфальтены образуют центральную часть (ядро) надмолекулярных структур, которые по классификации 3.И. Сюняева носят название сложных структурных единиц (CCE) [4].

В литературе часто описывают асфальтеновое ядро ССЕ в нефтях как квазисферические слоистые стэкинг-структуры толщиной 1,5-2,4 нм из плоских поликонденсированных ароматических молекул однородной плотности. Однако анализ наших исследований сырых нефтей по новой методике [1] показывает, что большая часть 70-90\% от фактического радиуса асфальтенового ядра $R$ представлена аморфными нерегулярными структурами с достаточно низкой степенью упорядочения. Это говорит о том, что ядро по структуре своей обладает не постоянной плотностью, которая уменьшается от центра ядра к его периферии. Такие особенности свойственны, так называемым, фрактальным объектам, математически описанные впервые Бенуа Мандельбротом [5] и чуть позже Енсом Федером [6]. В России фрактальные структуры впервые появились 
в публикациях Б.М Смирнова [7, 8]. К последним обзорам по фрактальным свойствам дисперсных систем относится работа В.И. Ролдугина [9], библиография которой включает 395 ссылок.

Фракталы (от латинского fractus- дробный) - это самоподобные геометрические фрагментированные объекты, структура которых сохраняется при переходе от малых до предельно больших линейных масштабов (скейлинговая инвариантность), размерность которых описывается дробным числом и отличается от топологической [7]. Фрактальные агрегаты со своей уникальной структурой во многом предопределяют физико-химические макрохарактеристики нефтяных коллоидных систем в целом. Поэтому фрактальные агрегаты были и остаются бесспорными лидерами по числу работ, посвященных исследованию фракталов $[9,10]$.

Основное свойство нефтяных дисперсных систем - это непрерывная многоуровневая самосборка и перестройка сложных наноагрегатов при изменении термодинамических условий под воздействием природных и техногенных факторов [10]. Особое значение в этой перестройке играет фрактальная геометрия асфальтеновых агрегатов.

Для изучения структуры фрактальных агрегатов наряду с экспериментальными методами [9] широко используется компьютерное моделирование $[11,12]$, которое позволяет без существенных затрат проводить исследование сложных систем, не решаемых аналитическими методами. Компьютерные эксперименты в настоящее время занимают нишу между теорией и реальным физическим экспериментом, и позволяют визуально описать и прогнозировать физические свойства природных систем с большим (до 109) числом частиц. $\mathrm{B}$ качестве примера на рис.1. приведено изображение двумерного фрактального асфальтенового агрегата, полученного автором при компьютерном моделировании, имитирующим рост фрактальной структуры по решеточной модели DLA агрегации Виттена и Сандера [13], контролируемой диффузией. Представленный на рис. 1 фрактал радиусом 50 нм содержит 1000 
асфальтеновых малых частиц размером 1 нм. Моделирование проводилось методом Монте-Карло по специальной программе с учетом быстрой агрегации по Смолуховскому и вероятностью $\mathrm{P}=1$ осаждения частиц на кластер без применения межчастичных потенциалов взаимодействия. Как известно, молекулы асфальтенов электрически нейтральны и зарядовые взаимодействия не оказывают существенного влияния на их агрегацию в кластеры [3].

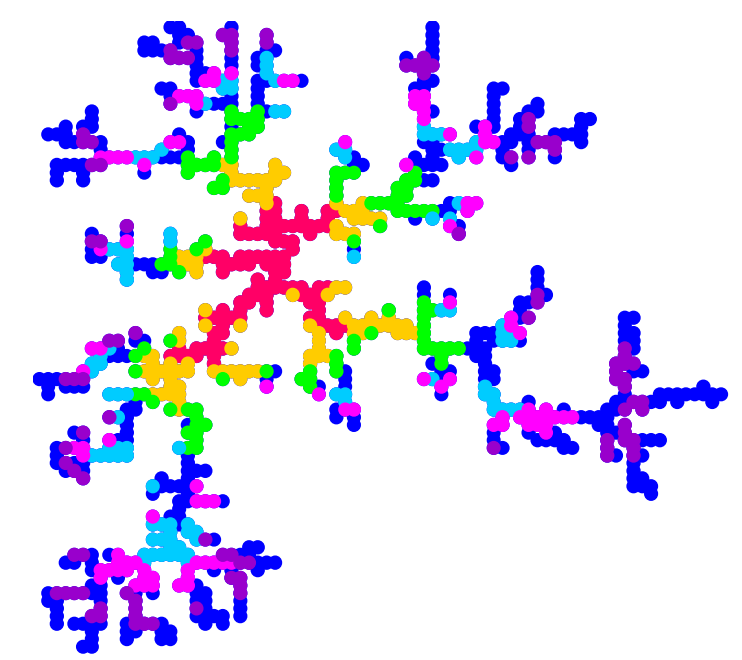

Рис.1. Изображение асфальтенового фрактального агрегата радиусом 50 нм, полученного по DLA модели агрегации Виттена и Сандера из частиц радиусом 1 нм. Цветом показан возраст частиц, агрегация которых идет от центра к периферии. Размерность фрактала $D=1,687$.

B решеточной модели DLA процесс выращивания стартует с первоначальной фиксированной центральной частицы, так называемое «зерно» роста кластера, которое помещается в точку с координатами $(0,0)$. В этот момент кластер состоит всего из одной связанной затравочной частицы. Затем со случайного положения в пространстве на большом расстоянии от частицызародыша запускается следующая свободная частица. За счет случайной броуновской диффузии она блуждает по узлам решетки до тех пор, пока не прилипнет к зародышу, либо уходит за границы области $\quad$ в бесконечность и выбывает из системы. Присоединение частицы к кластеру происходит тогда, когда сумма состояний ближайших к частице четырех узлов квадратной решетки отлична от нуля, то есть они не пустые. В случае прилипания частица превращается в связанную и кластер вырастает на один мономер. После этого 
вычисляется новое значение радиуса кластера. Далее в систему запускается следующая свободная частица, которая после случайных блужданий по узлам решетки также осаждается на зародыше из двух частиц. Этот процесс агрегации повторяется много раз, генерируя фрактальный кластер. Размер фрактала лимитируется заданием в модели максимального радиуса $R_{\max }$ границы роста. При реализации DLA-модели необходимо непрерывно определять минимальное расстояние между диффундирующей частицей и кластером и опрашивать текущие координаты всех частиц кластера. На всех этапах задания и перемещения частиц по узлам решетке с размерностью L x L пространственное движение частиц моделируется с помощью генератора случайных чисел, тем самым реализуется стохастический вероятностный закон роста, присущий природным кластерам. Вероятность присоединения новых частиц на периферии, как правило, выше, чем в глубине кластера, поэтому кластер имеет объемную разветвленную рыхлую структуру (рис.1), «склеенную» из набора малых частиц асфальтенов.

При всей внешней хаотичности, разорванности и неупорядоченности структуры полученного кластера на рис.1, подобные объекты, тем не менее, имеют внутренний порядок, который проявляется в наличии универсального степенного закона между числом частиц $N$ в агрегате и его радиусом $R[7,12]$ ( $R$ часто называют радиусом гирации):

$$
N(R)=k R^{D}
$$

где $k$ - постоянный коэффициент (префактор), $D$ - дробная (не целая) фрактальная размерность кластера, которая меньше топологической размерности пространства $d$ : для плоскости $d=2$ и для евклидова пространства $d=3$. Фрактальная размерность не зависит от формы кластера. Фрактальная размерность кластера отражает особенное свойство, а именно степень заполнения им пространства. Чем меньше фрактальная размерность $D$, тем 
более рыхлая (с меньшей густотой дендритных ветвей) структура кластера возникает в пространстве и больше пористость (пустотность) кластера. Это главное свойство фрактальных агрегатов аналитически описывается радиальной функцией $\rho(R)$ распределения плотности фрактала с увеличением его радиуса $\mathrm{R}:$

$$
\rho(R)=\rho(0)(R / r)^{D-d},
$$

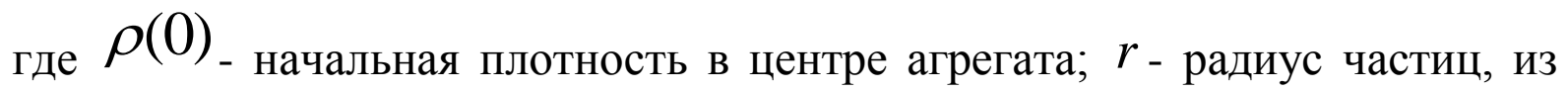
которых собирается фрактальный агрегат.

В природных объектах экспериментально установленная фрактальная размерность агрегатов изменяется в достаточно широких пределах от 1,3 до 2,9 ед.[6]. Для определения фрактальной размерности $D$ имеется много различных методов: седиментации, электронной и оптической спектроскопии, рассеяния света, рентгеновских лучей и нейтронов [9]. Например, часто используют уравнение (1), называемое массовым, так как количество $N$ частиц непосредственно отражает и их массу. Для расчета $D$ в этом случае вокруг центра фрактального агрегата задается несколько окружностей с различным текущим радиусом $R_{i}$ и проводится подсчет числа частиц, находящихся внутри каждого круга по мере увеличения радиуса фрактального кластера. В двойных логарифмических координатах модель (1) будет представлять прямую линию с угловым коэффициентом, равным $D$. В частности, структура модельного фрактала на рис. 1 описывается уравнением вида:

$$
N(R)=2.469 R^{1.687}
$$

с коэффициентом корреляции 0,999 д.ед. Из уравнения (3) следует, что фрактальная размерность $D$ составляет 1,687 ед. и по величине близка к теоретической 1,667 ед., рассчитанной по уравнению Флори [12].

Исследование фрактальных свойств реальных нефтей

Значительный интерес представляет оценка фрактальной размерности 
асфальтенового ядра комплексов ССЕ природных сырых нефтей, так как такие работы до сих пор не проводились.

На основе разработанного нового способа, использующего данные импульсного метода ЯМР $[1,2]$, нами впервые проведено измерение фрактальной размерности сырых нефтей различного геологического возраста.

Определение размеров ССЕ и асфальтенового ядра в нефтях основано на явлении сольватации молекул растворителя (жидких углеводородов) вблизи комплекса ССЕ. Радиус комплекса ССЕ рассчитывается по формуле $[1,2]$ :

$$
R_{C C E}=4,323 C\left(\frac{\rho_{n}}{\rho}\right)\left(\frac{T_{1 b}}{b}\right)^{0.1485}
$$

где ${ }^{C}$ - суммарная массовая концентрация асфальтенов $C_{a_{\text {и смол }}} C_{s m}$,

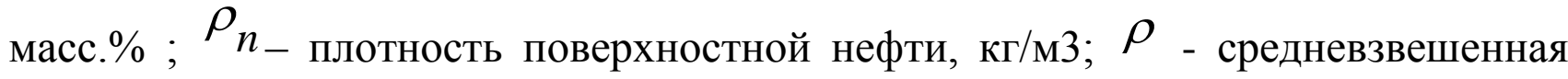
плотность дисперсной фазы, кг/м3; $T_{1 b}$ время спин-решеточной релаксации молекул углеводородов во внешней сольватной оболочке $\mathrm{CCE}, \mathrm{c} ; b$ - объемная доля по ЯМР сольватированных молекул, доли ед. Размеры асфальтенового ядра $R$ определяются с учетом радиуса $R_{C C E}$ :

$$
R=R_{C C E}\left(1+\frac{C_{s m}}{C_{a}} \frac{\rho_{a}}{\rho_{s m}}\right)^{1 / 3}
$$

Опыты проводились на протонном ЯМР-спектрометре (Брукер, Германия) c резонансной частотой 20 МГц, оснащенном системой термостабилизации датчика. Минимальное разрешение по нефти оставляет 1,5·10-3 г. Точность измерения амплитуды сигнала при соотношении сигнал/шум=100 составляет $0,4 \%$ отн., а времен релаксации - $2 \%$ отн.

Для расчета фрактальной размерности $D$ использовалась апробированная методика, основанная на соотношении логарифмов массы наноагрегатов и их линейных размеров [6]. На рис.2 приведены полученные экспериментальные 
графики связи массы и диаметра асфальтеновых наночастиц для исследованных 4-х групп сырых нефтей Пермского края. Из рисунка видно, что нефти различных геологических отложений четко дифференцируются по углу наклона линейных графиков. Ниже в сводной табл.1 приведены полученные экспериментальные результаты.

Установлено, что фрактальная размерность $D$ коррелирует с возрастом нефтей и монотонно увеличивается вниз по разрезу. Анализ показал, что нефти каменноугольных отложений (группы 1-3 в табл.1) в целом имеют близкие параметры $D$, среднее значение которых составляет $1,68 \pm 0,06$ ед. Но при этом нефти каменноугольной системы значительно (на 32,3 \% отн.) отличается по фрактальной размерности от ниже залегающих верхнедевонских нефтей. Максимальный размах $D$ оставляет 0,619 ед. или $38,6 \%$ отн.

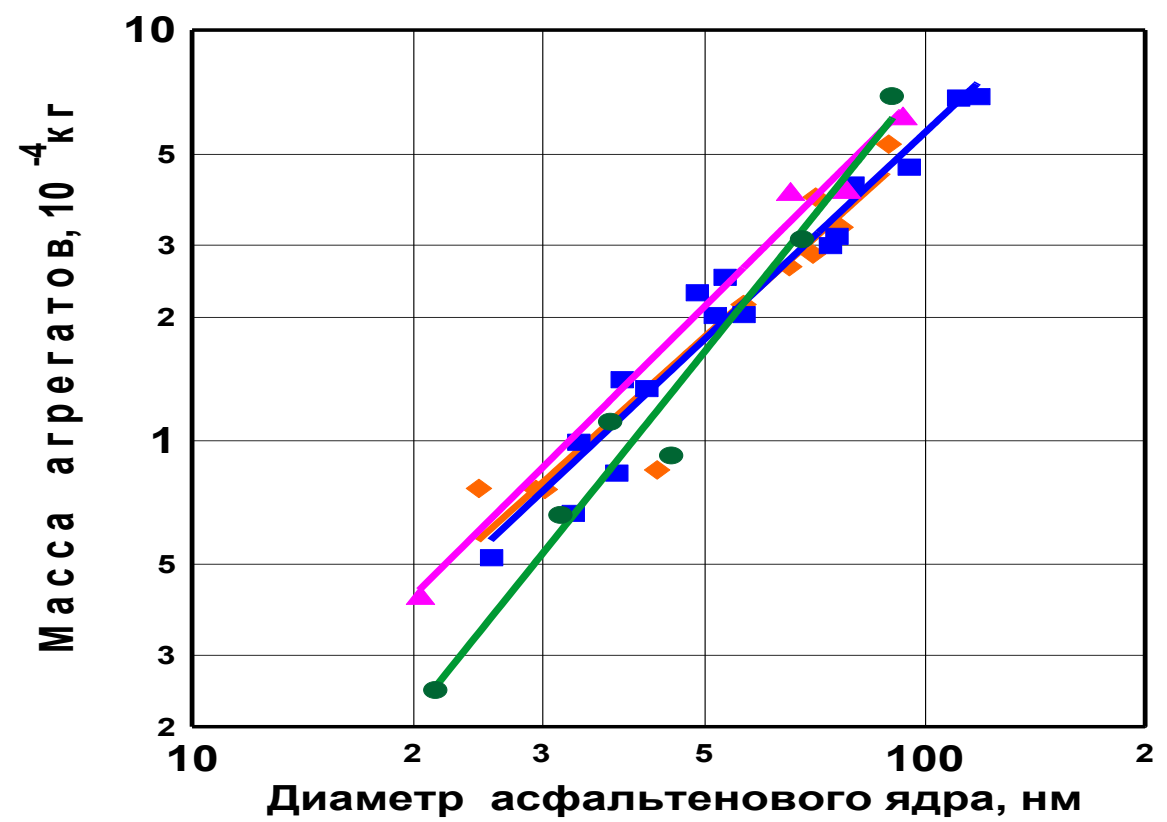

Рис.2. Зависимость массы наноагрегатов от диаметра ядра ССЕ для 4-х групп сырых нефтей Пермского края: - башкирские $\left(\mathrm{C}_{2 \mathrm{~b}}\right) ; \mathbf{-}$ - визейские $\left(\mathrm{C}_{1 \mathrm{v}}\right) ;$ турнейские $\left(C_{1 t}\right)$; - девонские $\left(D_{3 \mathrm{fm}}\right)$ отложения

Отсюда получается, что фрактальная размерность D структуры асфальтеновых агрегатов является интегральным генетическим признаком дифференциации природных нефтей, то есть степени ее «созревания» Данный вывод хорошо согласуется с результатами других исследований. Например, известно, что нефти Пермского края по данным ИК- 
спектроскопии в интервале 650-5000 см-1 характеризуются наличием четкой тенденции уменьшения степени окисления и содержания бензольной ароматики по мере увеличения геологического возраста нефтей по разрезу [14]. Следовательно, можно предположить, что высокое содержание ароматических углеводородов (аналогов бензола) в составе нефтей непосредственно влияет на механизм агрегации асфальтенов и способствует формированию неоднородных и рыхлых ядер ССЕ с низкой фрактальной размерностью.

Таблица 1

Фрактальная размерность и характеристики асфальтенового яора сложных структурных единиц нативных нефтей Пермского края

\begin{tabular}{|c|c|c|c|c|c|c|}
\hline $\begin{array}{l}\text { Номер } \\
\text { группы } \\
\text { нефтей }\end{array}$ & Система & Ярус & $\begin{array}{c}\text { Геологи- } \\
\text { ческий } \\
\text { возраст, } \\
\text { млн. лет }\end{array}$ & $\begin{array}{c}\text { Фрак } \\
\text {-таль-ная } \\
\text { размер- } \\
\text { ность, ед. }\end{array}$ & $\begin{array}{c}\text { Средняя } \\
\text { плот-ность } \\
\text { ядра, } \\
\text { кг/м } \\
\end{array}$ & $\begin{array}{c}\text { Средняя } \\
\text { порис-тость } \\
\text { ядра, }\end{array}$ \\
\hline 1 & \multirow{3}{*}{$\begin{array}{l}\text { Каменно- } \\
\text { угольная }\end{array}$} & Башкирский $\mathrm{C}_{2 \mathrm{~b}}$ & $308-316$ & 1,604 & 974 & 39,1 \\
\hline 2 & & Визейский $\mathrm{C}_{1 \mathrm{v}}$ & $328-342$ & 1,676 & 1109 & 30,7 \\
\hline 3 & & Турнейский $\mathrm{C}_{1 \mathrm{t}}$ & $345-356$ & 1,774 & 1199 & 25,1 \\
\hline 4 & Девонская & Фаменский $\mathrm{D}_{3 \mathrm{fm}}$ & $357-364$ & 2,223 & 1274 & 20,4 \\
\hline \multicolumn{4}{|c|}{ Среднее значение для всей выборки } & 1.701 & 1139 & 28,8 \\
\hline
\end{tabular}

В общем случае на фрактальную размерность $D$ влияют различные внешние условия самосборки асфальтеновых агрегатов. Так, усложнение траектории движения отдельных частиц до столкновения от прямолинейного до броуновского скачкообразного приводит к снижению фрактальной размерности от 1,92 до 1,68 ед. [7]. Напротив, уменьшение вероятностного фактора агрегации $\mathrm{P}$ от 1,0 до 0,1 ведет к увеличению фрактальной размерности $D$ от 1,68 до 1,73 ед. за счет увеличения глубины проникновения частиц от периферии к центру и их осаждению на внутренних ветвях кластера. Размерность во всех случаях выступает как интегральный показатель интенсивности накопления массы фрактала с ростом его радиуса $R$ [7, 12]. Вышесказанное подтверждается результатами прямого компьютерного моделирования с различными модификациями DLA-модели 
агрегации Виттена и Сандера, отвечающей конкретным физическим условиям агрегации фрактальных структур [10].

В целом фрактальная размерность отражает процесс самоорганизации сложной системы под действием физико-химических полей и тесно связана с термодинамическими параметрами ее состояния. Во всех случаях, и в состоянии равновесия и на пути к нему, образование неправильной изрезанной «шероховатой» поверхности фрактального кластера является термодинамически выгодным процессом, способствующим уменьшению свободной энергии, по сравнению с агрегатами с правильной геометрией. Дополнительными свойствами фрактальных структур является высокая способность захватывать большое пространство при использовании малого количества вещества, более высокая седиментационная устойчивость в силу меньшей плотности и рыхлой структуры, отсутствие энергетического барьера для образования критического зародыша [15].

В нашем случае при исследовании нефтей Пермского края установлено, что фрактальная размерность $D$ асфальтенового ядра непосредственно связана со свойствами дисперсионной среды, то есть жидких углеводородов. На рис.3а приведена корреляционная зависимость параметра $D$ и энергии активации $E_{a}$ молекулярных движений углеводородов для 4-х групп нефтей продуктивных отложений (см.табл.1). Энергия активации определялась стандартным методом ЯМР по данным температурных исследований [2]. Из рисунка видно, что увеличение энергии активации приводит к нелинейному снижению размерности агрегата, то есть понижению его плотности и усложнению пространственной структуры. Энергия активации, согласно уравнению Аррениуса [1], связана с потенциальным барьером, рост которого снижает диффузионную подвижность молекул и, тем самым, непосредственно влияет на вероятностный фактор столкновения частиц, и сдвигает агрегацию в сторону роста периферийной ветвистой структуры кластера. 
С другой стороны, дисперсная фаза также влияет на размерность $D$. Установлено, что с увеличением среднего содержания асфальтенов в нефтях фрактальная размерность монотонно снижается (рис.3б). Это происходит за счет того, что повышение содержания асфальтеновых частиц в единице объема приводит к сокращению межчастичных расстояний и увеличивает вероятность быстрой агрегации по механизму столкновения 2-х, трех и более частиц [8]. Это приводит к преимущественному росту структуры в более доступных узлах контакта частиц, расположенных на выступах поверхности фрактала, что ведет к уменьшению размерности $D$.

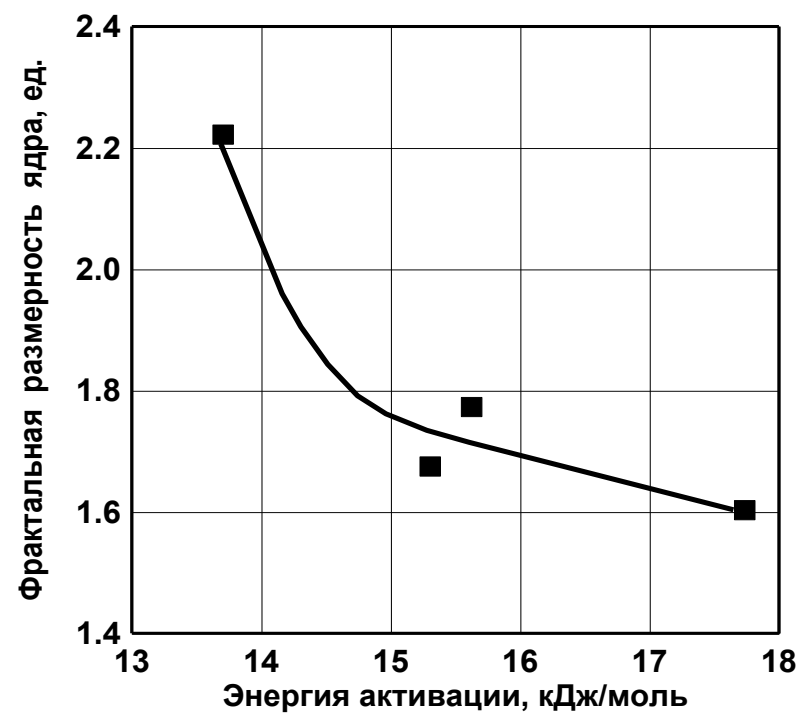

$\mathrm{a}$

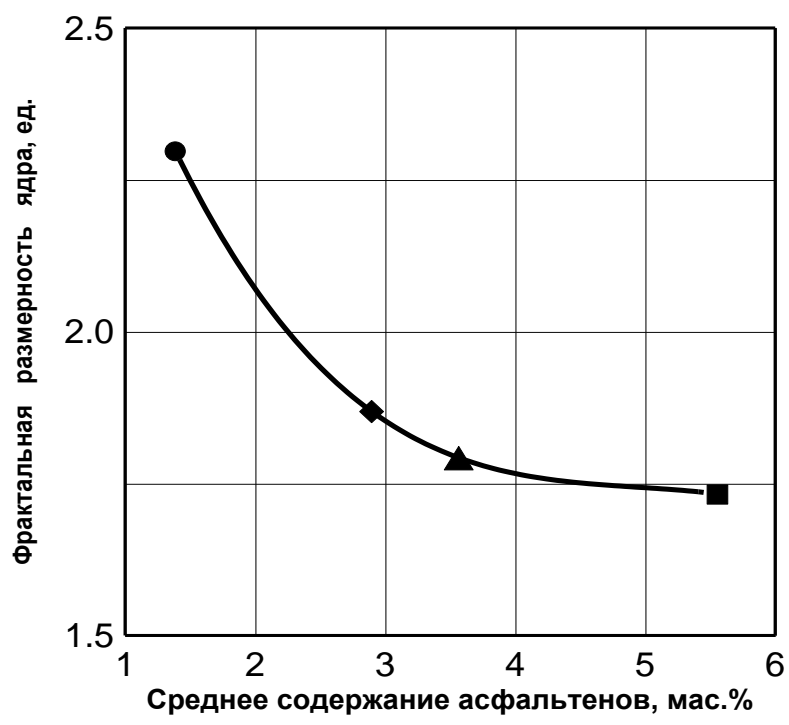

6

Рис.3. Зависимость фрактальной размерности асфальтеновых кластеров от энергии активации (а) и содержания асфальтенов (б) для 4-х групп нефтей Пермского края

Важным вопросом является влияние температурных полей на структуру асфальтеновых кластеров. Эксперименты показывают, что по мере увеличения температуры от 10 до 60 градусов происходит уменьшение размеров асфальтенового ядра в нефтях за счет деструкции [16], и снижение фрактальной размерности с 3 до 1,4 ед, (рис.4.). Таким образом, температура приводит к объемной перестройке фрактального кластера, которая затрагивает одновременно и внутреннюю, и периферийную части его ажурной структуры. 




Рис.4. Зависимость фрактальной размерности асфальтенового ядра от температуры для нативных нефтей Пермского края

Аналогичная температурная закономерность характерна, например, для формирования фрактальных дефектов в сплавах. Однако, в аэрозольных агрегатах, наоборот, наблюдается увеличения фрактальной размерности за счет спекания частиц и упрочнения агрегатов под действием высокой температуры [9].

С использованием описанного выше структурного подхода [1] впервые проведена оценка изменения реальной плотности фрактального асфальтенового ядра нативных нефтей. Если известна плотность нефти $\rho_{H_{\text {и }}}$ парциальные плотности дисперсионной среды и дисперсной фазы, то можно оценить среднюю плотность асфальтенов в нефтях in situ без операции осаждения асфальтенов гексаном или петролейным эфиром. В наших расчетах средняя экспериментальная плотность смол для нефтей Урала-Поволжья задавалась равной $\rho_{c м}=1025$ кг/м3 [17], а плотность углеводородов дисперсионной среды (растворителя) определялась по времени протонной спин-решеточной релаксации методом ЯМР.

На рис.5 для сырых нефтей различных месторождений построены зависимости средней плотности фрактального ядра ССЕ от его радиуса. Установлено, что по мере увеличения радиуса фрактальных асфальтеновых 
агрегатов их плотность уменьшается в 1,6-2,9 раза. Средняя плотность ядра для всей выборки экспериментальных точек составляет 1087 кг/м3, что на $13 \%$ отн. ниже средней плотности выделенных асфальтенов из диапазона 1100-1400 кг/м3. Вероятно, что при искусственном осаждении асфальтенов из нефти структура осадка получается более плотной за счет гравитационного сжатия и занижения эффективного объема частиц.

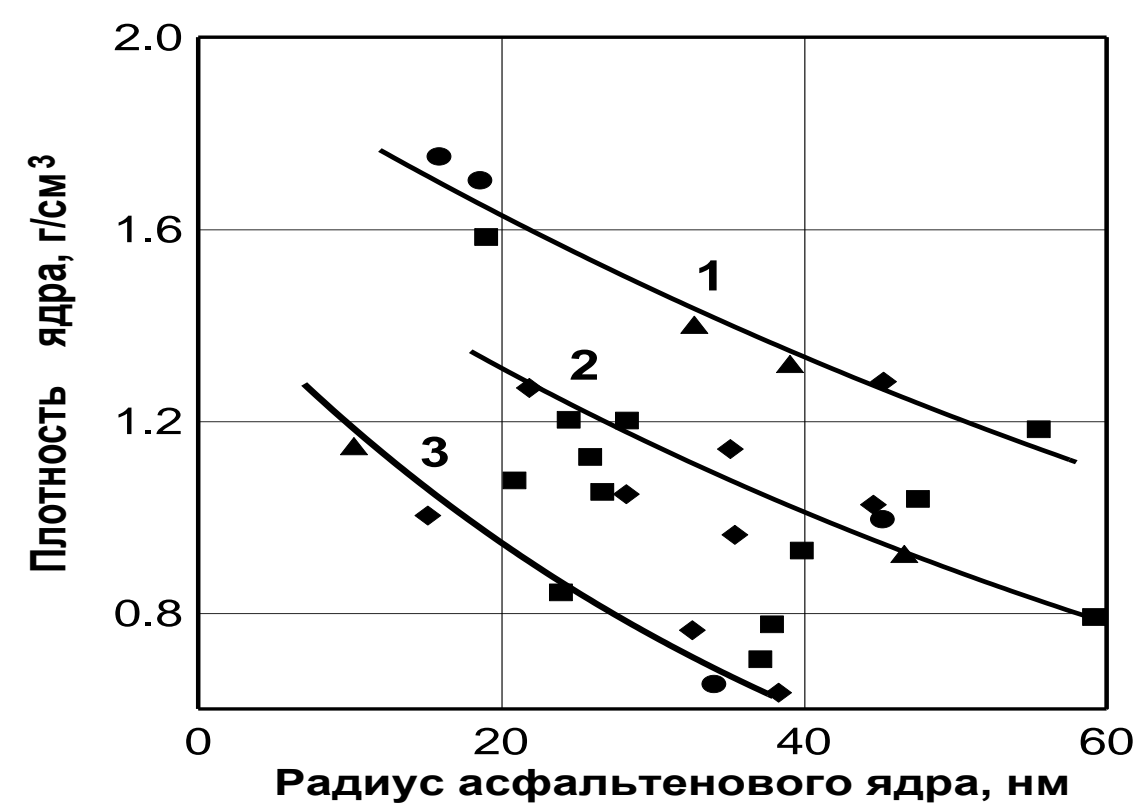

Рис.5. Зависимость средней плотности фрактального ядра ССЕ от его радиуса: 1,2,3 - группы нефтей с различной плотностью. Условные обозначения те же, что на рис. 2

Анализ данных показывает, что в случае с плотностью ядра принадлежность нефтей к различным геологическим отложениям не является значимым фактором и слабо влияет на корреляцию экспериментальных величин. Тем не менее, нами установлена выраженная регулярность, которая характеризуется дифференциацией опытных данных на три отдельные группы нефтей (графики 1-3 на рис.5).

Как показал анализ, такая закономерность, в первом приближении, объясняется различием средней плотности нефтей в группах: для первой она составляет 890 , второй - соответственно 880 и третьей -860 кг/м3. При 
равном радиусе асфальтенового ядра его плотность монотонно снижается от 1-ой группы к 3-й во всем диапазоне увеличения радиуса ядра. По всей видимости, плотность нефти не коррелирует с геологическим возрастом отложений и связана с другими факторами генезиса углеводородов.

Таким образом, в нефтях с изначально высокой плотностью углеводородов формируется и более плотное асфальтеновое ядро ССЕ. Тем самым подтверждается генетическая взаимосвязь физических свойств компонентов дисперсионной среды и дисперсной фазы.

Полученные на рис.5 графики однозначно подтверждают фрактальную природу асфальтеновых агрегатов, образование которых, по-видимому, напрямую зависит от индивидуального состава компонентов нефти. В конкретном случае средняя размерность $D$ по трем группам составляет $1,65 \pm 0,5$ и близка к средней величине по массовому методу из табл.1.

В табл.1 из опытов дополнительно приведены средние значения плотности ядра для 4-х групп сырых нефтей. Полученная корреляция плотности и фрактальной размерности хорошо согласуются с теорией согласно уравнению (2), так как при постоянстве параметров $d$ и $R$ плотность $\rho$ увеличивается с ростом фрактальной размерности $D$. С учетом плотности можно оценить также коэффициент пористости ядра или долю пустотного пространства внутри фрактала, не заполненного молекулами асфальтенов. Эта величина варьируется от 5 до 62 \%, а по группам в среднем составляет 20-39 \% (см. табл.1). Таким образом, сложная структурная единица представляет собой сферический агрегат из двух взаимовложенных фракталов: асфальтенового жесткого каркаса и бесструктурных нефтяных смол, заполняющих пустотное пространство внутри каркаса.

Большое разнообразие реологических и физических свойств добываемых нефтей обусловлено строением сложных структурных единиц дисперсной фазы. Особенность нефтяных дисперсных систем заключается в 
том, что размеры ядра ССЕ и сольватной оболочки не являются постоянными величинами и их реальное соотношение напрямую отражает процесс самосборки наноагрегатов из смол и асфальтенов [1].

Для изучения фрактальных свойств НДС автором был проведен комплексный анализ на более представительной статистике данных, включающей 353 пробы поверхностных нефтей, отобранным со 108 различных нефтяных залежей Пермского края.

Экспериментами установлено, что по мере увеличения массового содержания асфальтенов в нативных нефтях происходит непрерывный рост среднего радиуса асфальтенового ядра и снижение фрактальной размерности агрегатов. При этом на всем диапазоне изменения размеров ядра выделяется 4 неравнозначных интервала A, B, C и D, которые дифференцируются по ряду характерных признаков (содержанию смол и асфальтенов, динамики изменения размеров сольватной оболочки и ядра, фрактальной размерности). В табл.2 приведены полученные данные.

Нелинейное уменьшение фрактальной размерности от 2,969 до 1,768 при увеличении радиуса ядра от 5,8 до 65 нм отражает факт перестройки структуры комплекса ССЕ в сторону его усложнения, что отражается на всех макросвойствах нефтей (вязкости, плотности, температуре застывания и др.). В целом для нефтей реализуется общая закономерность снижения размерности в процессе роста агрегатов, которая была установлена ранее как при имитационном моделировании фрактальных кластеров [18], так и в реальных экспериментах по выращивания фрактальных кластеров [19]. При этом крутизна спада D полностью определяется начальными условиями роста кластеров. 
Таблийа 2

Интерваль радиуса асфальтенового ядра с различной фрактальной размерностью

\begin{tabular}{|l|l|l|l|l|}
\multicolumn{5}{|c}{ Интервалы радиуса асфальтенового ядра с различной фрактальной размерностью } \\
\hline $\begin{array}{l}\text { Код } \\
\text { интервала }\end{array}$ & $\begin{array}{l}\text { Интервал } \\
\text { радиуса ядра, } \\
\text { нм }\end{array}$ & $\begin{array}{l}\text { Содержание } \\
\text { асфальтенов, } \\
\text { масс. } \%\end{array}$ & $\begin{array}{l}\text { Средняя } \\
\text { фрактальная } \\
\text { размерность, } \\
\text { ед. }\end{array}$ & $\begin{array}{l}\text { Кол-во } \\
\text { точек }\end{array}$ \\
\hline A & $5,8-9,5$ & $0,1-0,4$ & 2,959 & 9 \\
\hline В & $10-20$ & $0,4-1,7$ & 2,057 & 78 \\
\hline C & $21-29$ & $1,8-3,0$ & 1,861 & 43 \\
\hline D & $30-65$ & $4,0-10,0$ & 1,768 & 223 \\
\hline
\end{tabular}

\section{Заключение}

1. С использованием решеточной модели агрегации Виттена-Сандера проведено моделирование роста асфальтенового фрактала и описаны его свойства;

2. Впервые измерена фрактальная размерность асфальтенового ядра сырых нефтей, которая корреллирует с геологическим возрастом нефтей.

3. Установлено влияние на фрактальную размерность энергии активации, содержания асфальтенов в нефтях и температуры опытов.

4. Впервые проведена оценка средней фрактальной плотности ядра ССЕ сырых нефтей и ее изменение с ростом радиуса ядра;

5. На представительной статистике данных экспериментально установлено монотонное уменьшение от 2,959 до 1,768 ед. фрактальной размерности асфальтенового ядра по мере увеличения радиуса.

6. Полученные результаты могут быть использованы при разработке современных методов управления свойствами нефтяных дисперсных систем. 


\section{Литература:}

1. Злобин А.А.. Экспериментальные исследования процессов агрегации и самосборки наночастиц в нефтяных дисперсных системах // Вестник Пермского национального исследовательского политехнического университета. Геология. Нефтяное и горное дело. - 2015.-№15.- С.5772.DOI:10.15593/2224-9923/2015.15.7.

2. Злобин А.А. Теория и практика применения ядерного магнитного резонанса в физике нефтяного пласта.- Пермь: «Издательство ПМ», 2015.-272 с.

3. Унгер Ф.Г., Андреева Л.Н. Фундаментальные аспекты химии нефти. Природа смол и асфальтенов.- Новосибирск: Наука. Сибирская издательская фирма РАН, 1995.-192 с.

4. Сюняев 3.И., Сюняев Р.З., Сафиева Р.3. Нефтяные дисперсные системы.- М.: Химия, 1990.-224 с.

5. Mandelbrot B.B. Fractals: Form, Chance and Dimension.-San Francisco: W.H.Freeman \&Co.-1977.-365 p.

6. Федер Е. Фракталы: пер. с англ.-М.: Мир,1991.-260 с.

7. Смирнов Б.М. Фрактальные кластеры // Успехи физических наук.- 1986.T.149, №.2.-c.178-219.

8. Смирнов Б.М. Физика фрактальных кластеров.- М.: Наука, 1991.-136 с.

9. Ролдугин В.И. Свойства фрактальных дисперсных систем // Успехи химии.2003.-Т. 72, вып.11.- С.1027-1054.

10. Структурная организация нефтяных дисперсных систем. / И.З. Мухаметзянов, И.Р. Кузеев, В.Г.Воронов , С.И. Спивак // Доклады. АН CCCP.- 2002.-T.387, №3.- C.353.

11. Хеерман Д.В. Методы компьютерного эксперимента в теоретической физике. Пер. с англ.-М.: Наука, 1990.-176 с.

12. Булавин Л.А., Выгорницкий Н.В., Лебовка Н.И. Компьютерное моделирование физических систем. Учебное пособие.- Долгопрудный: Интеллект, 2011.-352 с. 
13. Witten T.A., Sander L.M. Diffusien limited aggregation, a kinetic critical phenomenon // Physical Review Letters.- 1981. Vol.47, is. 19.- P.1400-1403. DOI:10.1103/ PhysRevLett.47.1400.

14. Коблова А.З.. Иванов Э.В. ИК-спектры поглощения нефтей Прикамья // Труды Камского отделения ВНИГНИ.- Пермь: Пермское книжное издательство, 1973.-Вып.123.-С.457-461.

15. Физическая природа разрушения // Кузеев И.Р., Куликов Д.В., Мекалова Н.В., Закирничная М.М..- Уфа: Изд-во УГТУ.-1997.-168 с.

16. Злобин А.А..Протопопов А.А. Структурно-энергетический метод выбора ингибиторов парафиновых отложений // Нефтяное хозяйство.-2014.-№6.C.48-51.

17. Глущенко В.Н., Силин М.А., Герин Ю.Г. Нефтепромысловая химия. Т.V. Предупреждение и устранение асфальтеносмолопарафиновых отложений.М.: Интерконтакт.- Наука.- 2009.- 475 с.

18. Высокотемпературные процессы и аппараты переработки углеводородного сырья// под ред. И.Р.Кузеева.- Уфа: Гилем.- 1999.- 32 с

19. Михайлов Е.Ф., Власенко С.С. Образование фрактальных структур в газовой фазе // Успехи физических наук.- 1995.-Т.165, №.3.-с.263-282. 